\title{
Influence of the Thickness on the Thermal Degradation of PMMA
}

\author{
CHRISTIAN VOVELLE, ROBERT AKRICH, JEAN-LOUIS DELFAU, \\ and SILVIE GRESILLAUD \\ Centre de Recherches sur la Chimie de la Combustion \\ et des Hautes Températures. C.N.R.S. \\ 1c Avenue de la recherche scientifique \\ 45045 Orleans-Cedex, France
}

ABSTRACT

The influence exerted by the initial thickness on the thermal degradation of PMMA has been studied experimentaliy. The mass loss rate and the temperature profile in the solid have been measured continuously for $.6,1.0,1.5,3.0$ and $5.0 \mathrm{~cm}$ thick specimens. All the experiments have been performed under nitrogen. The evolution of the thermal degradation has been interpreted in term of the two variables $R=\dot{m} " /\left(\dot{Q}^{\prime \prime}-\dot{Q}^{\prime \prime}\right)$ ) mass loss rate per unit heat flux absorbed by the material and $q^{\prime \prime}=\int_{0}^{k}\left(\dot{Q}^{\prime \prime}-\dot{Q}_{1}{ }_{1}\right) x d t$ amount of heat accumulated into the solid.

Two conclusions have been drawn from the experimental results :

-there exists a critical thickness below which the naximum mass loss rate depends on the initial thickness of the specimen.

-since this variation results from a change in the heat loss from the backside, it does not affect the curve $R=f\left(q^{\prime \prime}\right)$ except for very thin materials.

\section{INTRODUCTION}

This paper is concerned with the prediction of the mass loss rate of solid materials exposed to a radiant heat flux. This problem is of primary importance in fire development since it governs the height of the flame of the first buming object and therefore the secondary effects associated with this flame lair entrainment, flow rate of hot gases in the higher part of the room, radiation...). The thermal degradation of solid materials also plays a role in the prediction of the ignition delay of other objects (targets) or in the calculation of the rate of propagation of flames along surfaces.

Heat transfert in solid materials associated with pyrolysis and liberation of gaseous products has been extensively studied either theoretically $(1,2,3)$ or experimentally $(4,5,6)$. These studies lead to a good knowledge of the physical phenomena involved in thermal degradation. On the other hand, an examination of these investigations clearly shows that the kinetic parameters which govern the calculation of the rate of pyrolysis of solid materials are far from being well known (7). As a result, the use of a detailed model to calculate the mass loss rate of solid materials in a fire situation presents two inconveniences :

(i) the resolution of these models is time consuming, and

(ii) the results obtained are not specific enough. 
Presently, a simpler procedure derived from Tewarson's work is used in the computer codes for fire development $(9,10)$. Tewarson and Pion ( 8 ) have shown that for various materials, a linear relationship is observed between the mass burning rate and the heat flux absorbed by the material :

$$
\dot{\mathrm{m}}^{\prime \prime}=\left(\dot{Q}^{\prime \prime}-\dot{Q}^{\prime \prime}{ }_{\mathrm{Is}}\right) / \mathrm{L}_{\mathrm{G}}
$$

with :

$$
\begin{aligned}
& \dot{m} \quad \text { : mass burning rate per unit surface }\left(\mathrm{g} \cdot \mathrm{cm}^{-2} \cdot \mathrm{s}^{-1}\right) \\
& \dot{Q}^{\prime \prime} \quad \text { : incident heat flux }\left(\mathrm{W} \cdot \mathrm{cm}^{-2}\right) \\
& \dot{Q}^{\prime \prime}{ }^{\prime} \text { : heat loss from the surface }\left(\mathrm{W} \cdot \mathrm{cm}^{-2}\right) \\
& \mathrm{L}_{\mathrm{G}} \text { : heat of gasification of the material }\left(\mathrm{J} \cdot \mathrm{g}^{-1}\right)
\end{aligned}
$$

The main advantage of this relationship is simplicity since only one quantity $\left(I_{G}\right)$ is required for a given material. However it must be noticed that in the study of Tewarson, only the stationary state, characterized by a constant value of the mass burning rate has been considered and since the development of a fire in a room involves mainly transient phenomena, it was worth studying how the Tewarson relationship could be extended to non-stationary conditions. Therefore, a few years ago, an experimental study of the thermal degradation of two materials : PMMA and particle board, exposed to a radiant heat flux has been undertaken in our laboratory.

In a first step, the mass loss rate for each material was continuously measured during constant heat flux experiments in the range $O_{-}{ }^{4} W_{.} \mathrm{cm}^{-2}$. This study showed that when the variables $R=\dot{m} " /\left(\dot{Q}^{\prime \prime}-\dot{Q}^{\prime \prime}{ }_{1 s}\right)$ and $q^{\prime \prime}=\int_{0}^{t}\left(\dot{Q}^{\prime \prime}-\dot{Q}^{\prime \prime}{ }^{\prime}\right) x d t$ (with $t=$ duration of the exposition to the radiant flux) were used to describe respectively the "response" of the material and the progress of the overall thermal degradation process a unique curve was obtained for different values of the incident radiant flux (Q்") (11).

This curve increases continuously towards a maximum value corresponding to the stationary state. The continuous increase can be easily explained since during the transient heating stage, the heat absorbed by the material is partly transferred by conduction into the solid, and if the temperature is high enough, partly used to the pyrolysis of the material. Of course, a progressive increase of the second phenomenon and a progressive decrease of the first one is observed when the material is exposed to a constant heat flux.

From the unique curve obtained for experiments performed with different values of the incident radiant flux, it was concluded that the evolution of the ratio: heat used for the pyrolysis of the material/heat transferred by conduction is reproduced with similitude.

This similitude is interesting, since it shows that even during the transient stages preceding the stationary state, the mass loss rate of a given solid material can be predicted.

In a second step, the behavior of the same materials : PMMA and particle board, exposed to a variable radiant heat flux was considered (12). A linear variation with time of the radiant heat flux was produced. In term of the two variables :

$$
R=\dot{m}^{\prime \prime} /\left(\dot{Q} "(t)-\dot{Q}^{\prime \prime} 1(t)\right) \text { and } q^{\prime \prime}=\int_{0}^{t}\left(\dot{Q}^{\prime \prime}(t)-\dot{Q}^{\prime \prime}{ }_{1}(t)\right) \times d t
$$

the progress of the overall thermal degradation process was represented by the 
same curve as those obtained during the constant heat flux experiments.

Therefore, even when more realistic conditions, characterized by a continuous increase of the incident radiant flux are considered the diagram $R=f\left(q^{\prime \prime}\right)$ can be used to predict the mass loss rate of the solid material, at least for the two materials studied.

of course, some additional experiments performed with other materials are needed if one want to generalize the use of the diagram $R=f\left(q^{\prime \prime}\right)$ to predict the "response" of a solid material to thermal irradiation.

Another point had to be clarified. The previous experimental studies were performed with only one thickness of the specimens $: 1.5 \mathrm{~cm}$ for PMMA and $1.2 \mathrm{~cm}$ for particle board and the observation of a stationary state with this range of thickness could be questioned. The work presented in this paper aimed at an answer to this point. The evolution of the rate of thermal degradation of PMMA has been studied for various thickness of the specimens in the range $.6-5 \mathrm{~cm}$.

\section{EXPERIMENTAL}

The experiments have been carried out in a stainless steel chamber enclosing the radiant heat source, the specimen and the electronic balance (fig.1).

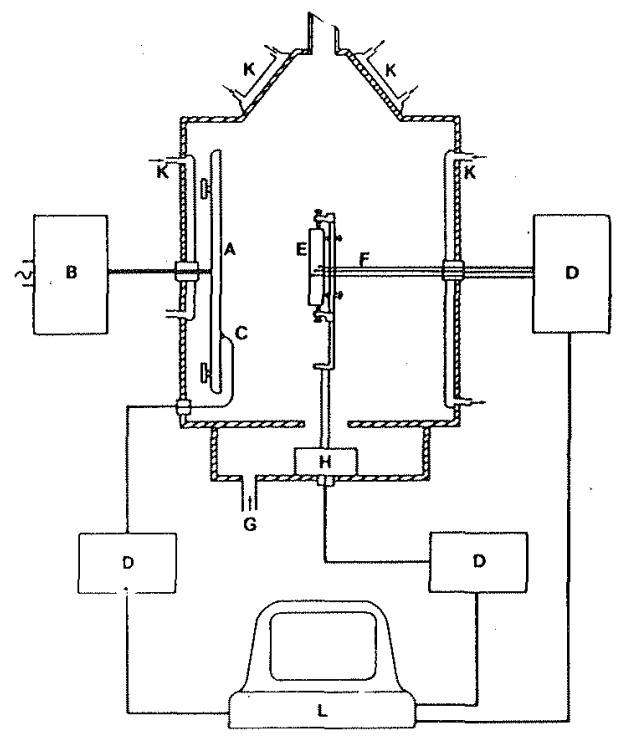

Figure 1 : Experimental device.

A : Radiant panel. B : Voltage regulator. C : Thermocouple. D : Analog-digital converter. E : Specimen. F : Thermocouples used for the measurement of the temperature profiles. $G$ : Gas inlet. $H$ : Electronic balance. $K$ : Water cooling. $L$ : Micro computer. 
An electrical panel of dimensions close to $.4 \times .4 \mathrm{~m}$ was used as a radiant source. The size of the specimens were small compared to the dimensions of the panel $(.1 \times .1$ or $.1 \times .06 \mathrm{~m})$ in order to ensure an homogeneous heat flux on the surface.

In this study, all the experiments were conducted with an incident radiant flux close to $3 \mathrm{~W} . \mathrm{cm}^{-2}$. This heat flux was controlled by a water cooled fluxmeter.

Kashiwagi pointed out that it is only when the flow rate of the pyrolysis products is low that the rate of thermal degradation of PMMA is affected by the oxygen content of the atmosphere surrounding the material (13). The same result was observed in our previous study (11). With $3 \mathrm{~W} . \mathrm{cm}^{-2}$, the effect of oxygen would only be observed during a short period corresponding to the beginning of the liberation of gaseous products, the subsequent pyrolysis steps being unaffected. Therefore, in this work the thermal degradation of PMMA was only studied in a nitrogen atmosphere. The nitrogen flow rate in the stainless steel chamber was equal to $3 \mathrm{~m}^{3} \mathrm{~h}^{-1}$.

The main part of the experiment consisted in the continuous measurement of the mass loss rate of the specimen. The calculation of the variables $R$ and $q^{\prime \prime}$ requires also a knowledge of the heat loss from each face of the material. Radiation as well as convection were taken into account in the calculation of these quantities :

$$
\begin{aligned}
& Q_{1 S}^{\prime \prime}(t)=\varepsilon \sigma\left(T_{S}{ }^{4}(t)-T_{\infty}{ }^{4}\right)+h\left(T_{S}(t)-T_{G}(t)\right) \\
& Q_{1 B}^{\prime \prime}(t)=\varepsilon \sigma\left(T_{B}{ }^{4}(t)-T_{\infty}{ }^{4}\right)+h\left(T_{B}(t)-T_{G}(t)\right)
\end{aligned}
$$

$T_{S}(t)$ and $T_{B}(t)$ represent the variation with time of the temperature of each face of the specimen. These quantities were not obtained from direct measurements. They were evaluated by extrapolation of the temperature profile measured with thermocouples located in small holes (.5 $\mathrm{mm}$ diameter) drilled parallel to the face exposed to the radiant flux, at increasing distances from this face. Twelve "thermocoax" thermocouples (external diameter $=.34 \mathrm{~mm}$ ) were used for the measurement of the temperature profiles.

The value of $E(.8)$ and $h\left(5 \times 10^{-4}\right.$ W.cm $\left.m^{-2} \cdot K^{-1}\right)$ used previously (12) have been used again for the calculation of $\dot{Q}^{\prime \prime} 1 \mathrm{~s}$ and $\dot{Q}^{\prime \prime} 1 \mathrm{~B}$.

The first objective of this work was to verify that the PMMA specimens used previously were thick enough for a stationary state to be observed (these specimens were $1.5 \mathrm{~cm}$ thick). Thicker specimens $(3.0$ and $5.0 \mathrm{~cm}$ ) were studied to clarify this point. To complement this work, it was interesting to consider the behavior of thinner specimens also, so that additional experiments were conducted with specimens of thickness equal to 1.0 and $.6 \mathrm{~cm}$.

\section{RESULTS AND DTSCUSSION}

The variation with time of the mass loss rate for samples with five thickness has been plotted on figure 2. These curves seem to indicate that the thickness used previously could lead to a stationary state since a maximum value close to $1.1 \times 10^{-3} \mathrm{~g} \cdot \mathrm{cm}^{-2} \cdot \mathrm{s}^{-1}$ is obtained for $1.5,3.0$ and $5.0 \mathrm{~cm}$. The plateau observed on the 5.0 curve confirms that this maximum value corresponds effectively to a stationary state. 


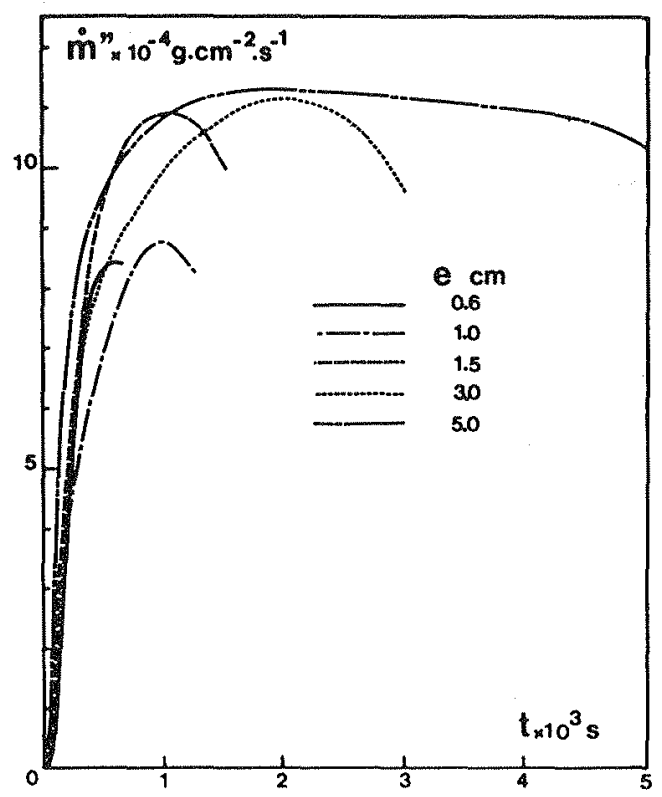

Figure 2: Influence of the initial thickness on the variation with time of the mass loss rate. PMMA under nitrogen.

On the other hand, a difference is observed with the thinner specimens : the maximum mass loss rate is only $8.5 \times 10^{-4} \mathrm{~g} \cdot \mathrm{cm}^{-2} \cdot \mathrm{s}^{-1}$ for $1.0 \mathrm{~cm}$ and slightly lower $\left(8 \times 10^{-4} \mathrm{~g} \cdot \mathrm{cm}^{-2} \cdot \mathrm{s}^{-1}\right)$ for $.6 \mathrm{~cm}$. It must be noticed that the thinner specimens $\left(.6\right.$ and $1.0 \mathrm{~cm}$ ) have been exposed to a radiant flux of $2.8 \mathrm{w} . \mathrm{cm}^{-2}$ instead of $3.0 \mathrm{~W} . \mathrm{cm}^{-2}$. This difference in the incident radiant flux is partly responsible for the lower value measured for the maximum mass loss rate. However, from the inear dependence observed previously for PMMA between the maximum mass loss rate and the incident radiant flux, the decrease of the flux from 3.0 to $2.8 \mathrm{~W} . \mathrm{cm}^{-2}$ would lead to a corresponding decrease of the maximum mass loss rate from $1.1 \mathrm{~g} \cdot \mathrm{cm}^{-2} \cdot \mathrm{s}^{-1}$ to $1 \mathrm{~g} \cdot \mathrm{cm}^{-2} \cdot \mathrm{s}^{-1}$. Hence, the difference observed with the thicker specimens can not be totally explained by a difference in the radiant flux but is also an effect of the thickness.

It was interesting to consider whether the decrease in the maximum mass loss rate for thickness lower than a critical value was also observed when the variables $\mathrm{R}$ and $\mathrm{q}^{\prime \prime}$ are used to describe the evolution of the thermal degradation process. Prior to the calculation of these variables, the heat loss from each face had to be evaluated from the variation with time of the temperature profiles in the material. These profiles have been plotted on figures (3-7). To illustrate the degree of accuracy of the temperature measurements, the points resulting from four distinct experiments have been plotted for the $5.0 \mathrm{~cm}$ thick specimens (fig.7). The variation with time of the temperature of each face was obtained by extrapolation of these profiles. The temperatures of the exposed surface for the five thickness studied have been plotted on figure 8 , while the corresponding curves for the rear face of the specimens have been plotted on figure 9 .

The profiles measured in the thicker specimens $(3.0$ and $5.0 \mathrm{~cm}$ ) show very 


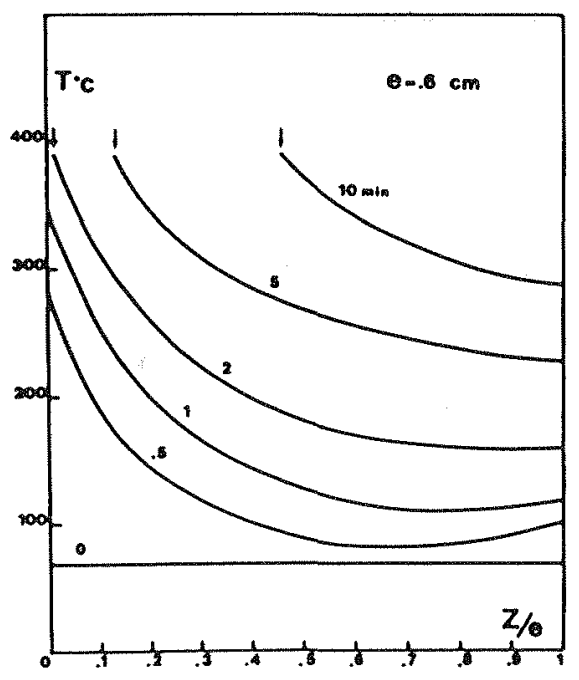

Figure 3 : Evolution with time of the temperature profile. $\dot{Q}^{\prime \prime}=2.8 \mathrm{~W} \cdot \mathrm{cm}^{-2}$

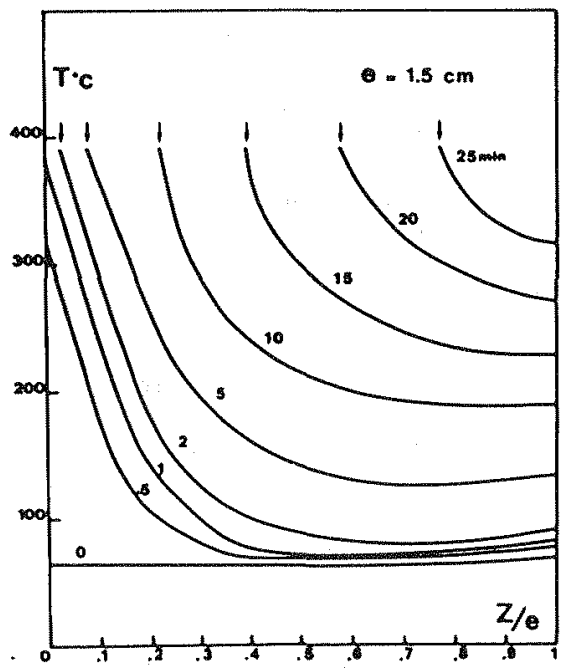

Figure 5 : Evolution with time of the temperature profile. $\dot{Q}^{\prime \prime}=3.0 \mathrm{~W} \cdot \mathrm{cm}^{-2}$

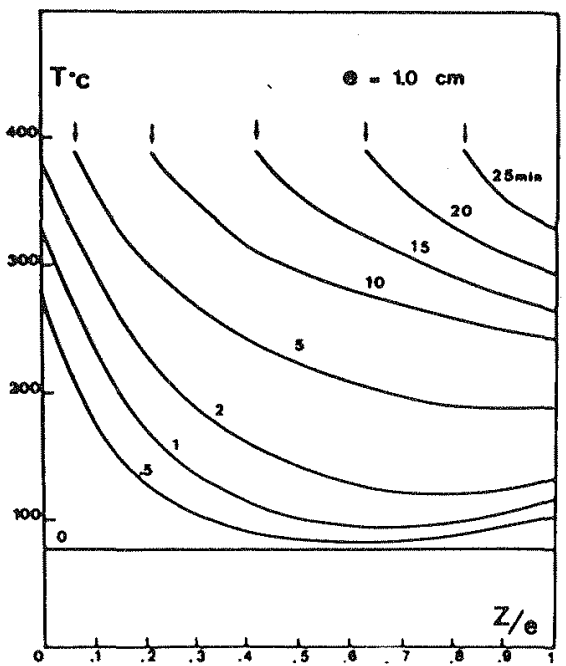

Figure 4 : Evolution with time of the temperature profile. $\dot{Q}^{\prime \prime}=2.8 \mathrm{~W} . \mathrm{cm}^{-2}$

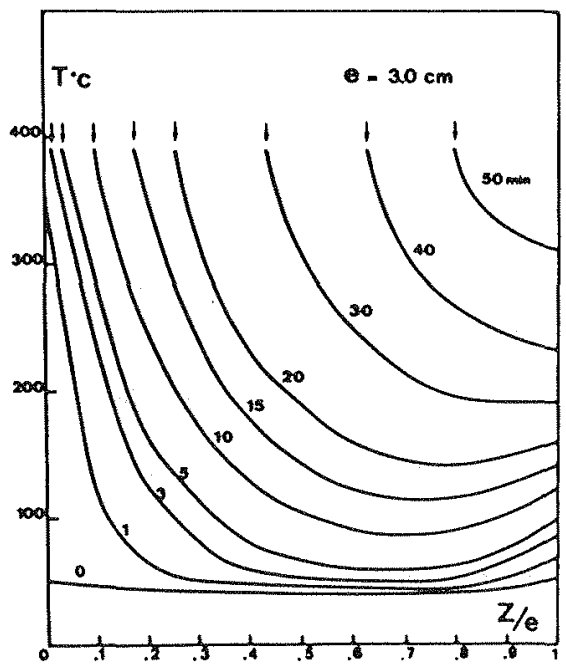

Figure 6 : Evolution with time of the temperature profile. $\dot{Q}^{\prime \prime}=3.0 \mathrm{~W} . \mathrm{cm}^{-2}$

clearly that despite the water cooling of the walls of the chamber, the temperature of the gas behind the specimen increases up to a value close to $200^{\circ} \mathrm{C}$. As a result of this temperature increase, a heating of the rear face of the specimen is observed. Since the temperature of the gas phase was not measured during these experiments, we have considered that the term $\mathrm{T}_{G}(t)$ in the equa- 


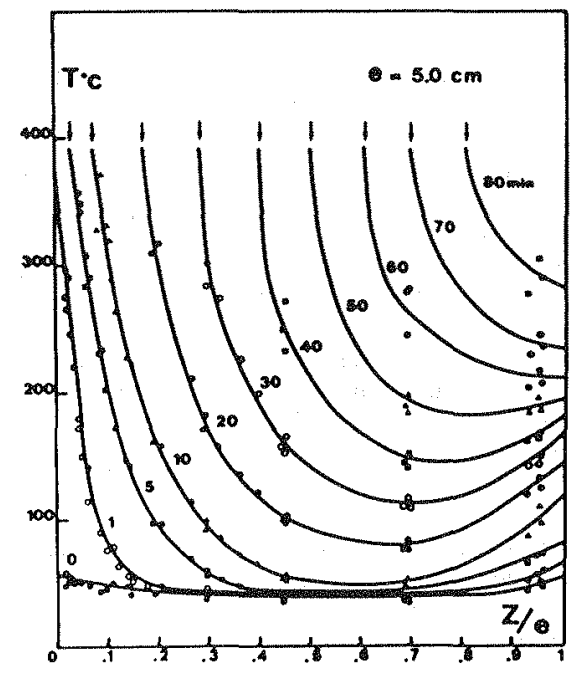

Figure 7 : Evolution with time of the temperature profile. $\dot{Q}^{\prime \prime}=3.0 \mathrm{~W} . \mathrm{cm}^{-2}$

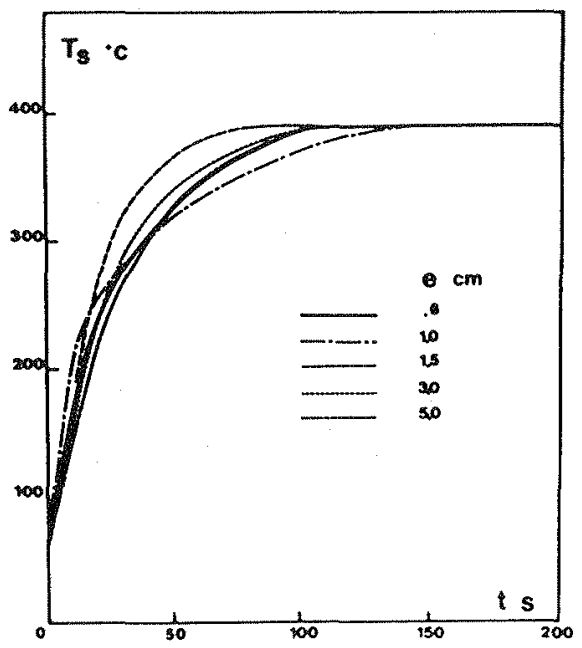

Figure 8 : Variation with time of the temperature of the exposed surface.

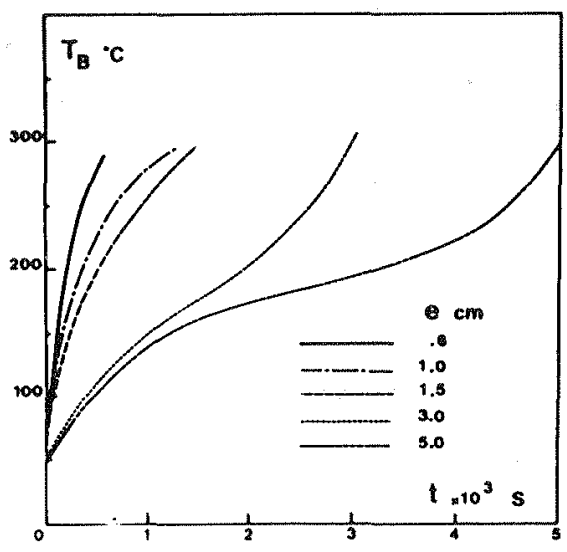

Figure 9 : Variation with time of the backside temperature.

tions 2 and 3 is equal to $T_{B}(t)$ up to $200^{\circ} \mathrm{C}$ and remains equal to this value when $\mathrm{T}_{\mathrm{B}}(t)$ becomes higher.

This assumption leads to keep the convective transfer between the gas and the material to a null value until $\mathrm{T}_{\mathrm{B}}(t)$ becomes higher than $200^{\circ} \mathrm{C}$. A more rigorous procedure would require a calculation of the heat transferred into the solid by convective heating of the surface. However a rough estimation of this 
term shows that its contribution to the overall thermal balance is negligible.

The temperature of the face exposed to the radiant flux increased very rapidly up to a constant value equal to $390^{\circ} \mathrm{C}$ (fig.8). This surface temperature is close to the value measured in different experimental conditions (13, 14). It can be seen that the thickness does not affect the rate of increase of the temperature of the face exposed to the radiant flux. As a result, the heat balance for this face does not depend on the thickness of the material. Obviously, the variation with time of the rear face temperature is strongly dependent on the initial thickness of the specimens.

For the thicker specimens $(3.0$ and $5.0 \mathrm{~cm})$ the curve $\mathrm{T}_{\mathrm{B}}=f(t)$ exhibits an inflection corresponding to the transition between the initial convective heating of the material by the gas located behind the specimen and the heating by conduction from the exposed surface when the regression of this surface decreases to a low value the thickness of the specimen.

Since the heat transfer at the exposed surface is not affected by the initial thickness of the specimens, the decrease in the maximum mass loss rate observed under a critical thickness can only be explained by a difference in the heat balance at the rear face.

This is illustrated in Figure 10 where the variation with the initial thickness of the maximum mass loss rate has been compared to the variation of the heat loss from the rear face of the specimen. For this comparison, the value of the heat loss calculated when the mass loss rate is maximum has been considered. These two curves show clearly that it is the increase in the heat

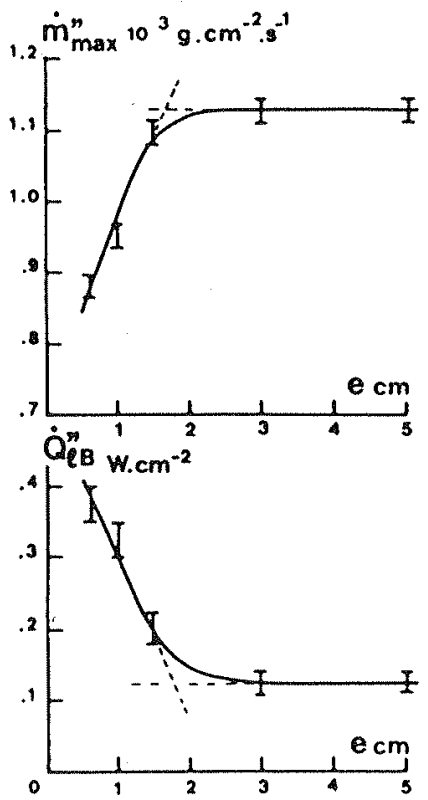

Figure 10 : Variation with e of $\dot{m}^{\prime \prime} \max$ and $\dot{Q}^{\prime \prime} 1 B^{*}$

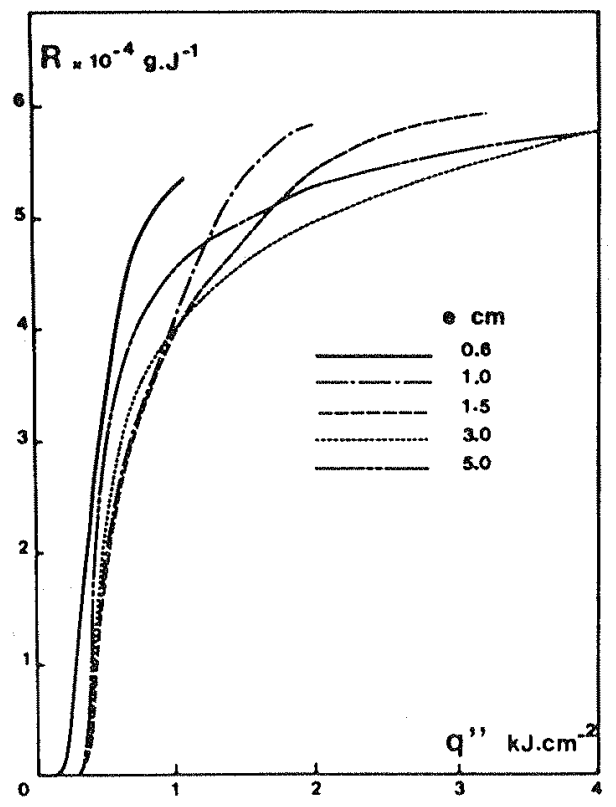

Figure 11 : Variation of the ratio $R=\dot{m}^{\prime \prime} /\left(\dot{Q}^{\prime \prime}-\dot{Q}^{\prime \prime}\right)$ vs $q^{\prime \prime}=\int_{0}^{t}\left(\dot{Q}^{\prime \prime}-\dot{Q}^{\prime \prime}{ }_{1}\right) \times d t$. 
loss from the backside of the specimens when the initial thickness is lower than a critical value, which is responsible for the decrease in the maximum mass loss rate. From these diagrams, a value close to $1.7-1.8 \mathrm{~cm}$ can be estimated for the critical thickness.

The dependence of the maximum mass loss rate on the heat los from the backside can be also evidenced by considering the variables $R$ and $q^{\prime \prime}$. The curves $R=f\left(q^{\prime \prime}\right)$ have been plotted on figure 11 for the five thickness studied. It can be seen that the ratio $R$ tends towards an unique value comprised between 5.5 and $6.0 \mathrm{~g} . \mathrm{J}^{-1}$. This maximum value corresponds to the stationary state and, according to the Tewarson relationship, is equal to the inverse of the heat of gasification of the material. This leads to a value in the range 1666-1818 J.g, in close agreement with the value measured by Tewarson for PMMA.

For the 1.0 to 5.0 thick specimens, the differences observed in the evolution of the curves $R=f\left(q^{\prime \prime}\right)$ must be attributed to the accuracy of the measurements, especially to the determination of $\mathrm{T}_{\mathrm{S}}(\mathrm{t})$. On the other hand, for the thinnest specimens, the ratio R starts to increase for lower values of $q^{\prime \prime}$. In that case, the increase in the heat loss from the backside is fast enough to change the overall heat balance the moment the exposure to the radiant flux starts.

\section{CONCLUSION}

In a previous study, we shoyed that it was very convenient to use the variables $R=\dot{m}^{\prime \prime} /\left(\dot{Q}^{\prime \prime}-\dot{Q}_{1}^{\prime \prime}\right)$ and $q^{\prime \prime}=\int_{0}^{t}\left(\dot{Q}^{\prime \prime}-\dot{Q}^{\prime \prime}{ }_{1}\right) \times d t$ to describe the thermal degradation of PMMA and particle board. The main advantage of these two variables is that a unique curve is obtained for experiments performed with different values of a constant incident radiant flux or with a variable radiant flux. This curve exhibits a maximum, and the main objective of this work was to check whether this maximum can be attributed or not to a stationary state. To give an answer to this question, some new experiments have been performed with PMMA specimens of thickness ranging between .6 and $5.0 \mathrm{~cm}$.

The simultaneous mass loss rate and temperature profiles measurements have led us to the conclusion that under a critical thickness, an increase of the heat loss from the backside of the specimens and a corresponding decrease in the maximum mass loss rate is observed. With the experimental conditions used in this study (thermal degradation of PMMA under nitrogen, incident radiant flux close to $3.0 \mathrm{~W} . \mathrm{cm}^{-2}$ ) this critical thickness is equal to $1.7-1.8 \mathrm{~cm}$. It can be considered that the conclusions drawn from the previous experiments remain valid, despite of a thickness of the specimens $(1.5 \mathrm{~cm})$ slightly too low.

The main interest of this work is that it confirms that the use of the variables $R$ and $q^{\prime \prime}$ to represent the thermal degradation of a solid material (at least for PMMA) leads to a simplification since except for very thin materials, the evolution of these quantities is not affected by the initial thickness of the material.

\section{NOMENCLATURE}

e : specimen thickness $(\mathrm{cm})$
$\mathrm{I}_{\mathrm{G}} \quad$ : Heat of gasification of the solid $\left(\mathrm{J} \cdot \mathrm{g}^{-1}\right)$
$\dot{\mathrm{m}}^{\prime \prime} \quad$ : Mass loss rate per unit surface $\left(\mathrm{g} \cdot \mathrm{cm}^{-2} \cdot \mathrm{s}^{-1}\right)$. 
Q" : Incident radiant flux $\left(W \cdot \mathrm{cm}^{-2}\right)$.

Q"1 : Total heat loss $\left(W . \mathrm{cm}^{-2}\right)$.

$\dot{Q}^{\prime \prime}{ }^{1}$ : Heat loss from the exposed surface $\left(W \cdot \mathrm{cm}^{-2}\right)$.

$\dot{Q}^{\prime \prime}$ ls : Heat loss from the backside $\left(W \cdot \mathrm{cm}^{-2}\right)$.

$\mathrm{q}^{\prime \prime}$ : Heat accumulated into the solid $\left(\mathrm{J} . \mathrm{cm}^{-2}\right)$.

$t$ : duration of the exposition to the radiant flux (s).

$\mathrm{T}_{\mathbf{S}}$ : Surface temperature (K).

$\mathrm{T}_{\infty}^{\mathrm{s}}$ : Ambient temperature (K).

$\mathrm{T}_{\mathrm{B}}$ : Backside temperature $(K)$.

$\mathrm{T}_{\mathrm{G}}$ : Temperature of the gas phase surrounding the material (K).

: enissivity of the surface.

h : Convective heat transfer coefficient $\left(W \cdot c \mathrm{~m}^{-2} \cdot \mathrm{K}^{-1}\right)$.

z : Distance from the exposed surface $(\mathrm{cm})$.

\section{REFERENCES}

1. Kansa, E.J., Perlee, H.E. and Chaiken, R.F.: "Mathematical model of wood pyrolysis including internal forced convection," Combustion and Flame, 29, 311-324, (1977).

2. Kung, H.C.: "The combustion of vertical wooden slab," 15 th Symposium (international) on Combustion, The Combustion Institute, Pittsburgh, 243-253, (1974).

3. Kashiwagi T.: "A radiative ignition model of a solid fuel," Combust. Sci. and Technol., 8, 225-236, (1974).

4. Kashiwagi T.: "Experimental observation of radiative ignition mechanisms" Combust. and Flame, 34, 231-244, (1979).

5. Becker, H.A., Phillips, A.M., and Keller, J.: "Pyrolysis of white pine," Combust. and Flame, 58, 163-189, (1984).

6. Petrella, R.V.: "The mass buming rate of polymers, wood and organic liquids," J. of Fire and Flammability, 11, 3, (1980).

7. Vovelie, C., Mellottee, H., and Delbourgo, R.: "Kinetics of the thermal degradation of cellulose and wood in inert and oxidative atmosphere" 19th Symposium (international) on Combustion, The Combustion Institute, Pittsburgh, 797-805, (1983).

8. Tewarson, A., and Pion, R.F.: "Flammability of plastics. I Burning intensity," Combust and Flame", 26, 85-103, (1976).

9. MitIer, H.E., and Emmons, H.W., : Documentation for CFC V, the Fifth Harvard Computer Code, NBS-GCR-81-344, (1981).

10. Curtat, M., and Bodart, X.: Point sur le Modèle C.S.T.B. de Développement du Feu dans une Pièce unique. C.S.T.B., Centre de Recherches de Marne la Vallée, (1983).

11. Vovelle, C., Akrich, R., and Delfau, J.L.: "Mass Loss rate measurements on solid materials under radiative heating," Combust. Sci. and Technol. $36,1-18$, (1984).

12. Vovelle, C., Akrich, R., and Delfau, J.L.: "Thermal degradation of solid materials under a variable radiant heat flux," 20th symposium (international) on Combustion, The Combustion Institute, Pittsburgh, In Press.

13. Kashiwagi, T., and Ohlemiller, T.J.: "Study of oxygen effects on nonflaming transient gasification of PMMA and PE during thermal irradiation," 19th Symposium (international) on Combustion, The Combustion Institute, Pittsburgh, 815-823, (1982).

14. Fernandez-Pello, A., and Williams, F.A.: "Laminar flame spread over PMMA surfaces," 15 th Symposium (international) on Combustion, The Combustion Institute, Pittsburgh, 217-231, (1974). 